\title{
A Facile Electrochemical Method to Prepare Pt Disk Electrode with (100) Preferential Orientation for Investigating Structure- Sensitive Electro-Oxidation Reactions
}

Zhi Liu ${ }^{1}$, Yao Yang ${ }^{1}$, Baipo Shu ${ }^{3, *}$, Jie Liu ${ }^{2}$, Xu Chen ${ }^{1}$, Yingbo Li ${ }^{2}$, Yida Deng ${ }^{2}$, Xiaopeng Han ${ }^{2}$, Wenbin $\mathrm{Hu}^{1,2}$, Cheng Zhong ${ }^{2, *}$

${ }^{1}$ State Key Laboratory of Metal Matrix Composites, Shanghai Jiao Tong University, Shanghai, 200240, China

${ }^{2}$ Key Laboratory of Advanced Ceramics and Machining Technology (Ministry of Education) and Tianjin Key Laboratory of Composite and Functional Material, Department of Materials Science and Engineering, Tianjin University, Tianjin 300072, China

${ }^{3}$ Faculty of Materials Science and Engineering, Kunming University of Science and Technology, Kunming 650093, China.

*E-mail: cheng.zhong@ tju.edu.cn (C. Zhong); sbp20020@126.com (B.P. Shu)

doi: $10.20964 / 2016.06 .28$

Received: 9 March 2016 / Accepted: 30 March 2016 / Published: 4 May 2016

A square-wave voltage was used to electrochemically treat the Pt disk electrode with $5 \mathrm{~mm}$ diameter in $\mathrm{H}_{2} \mathrm{SO}_{4}$ solution by a two-electrode cell. The surface preferential orientation of a $\mathrm{Pt}$ disk electrode can be controlled by the lower potential limit and the frequency of the square-wave voltage. The lower potential limit of $-2.4 \mathrm{~V}$ and the frequency of $2000 \mathrm{~Hz}$ resulted in the formation of (100)-oriented $\mathrm{Pt}$ surface on the disk electrode. Hydrogen desorption profile suggested the significantly increased proportion of $\mathrm{Pt}(100)$ sites in the electrochemically treated $\mathrm{Pt}$ disk electrode. Four typical and important structure-sensitive electro-oxidation reactions were selected for investigating the electrocatalytic activity of Pt electrodes. Electrochemically treated Pt disk electrodes exhibited much higher specific activities for the electro-oxidation of ethanol and ammonia, and revealed lower specific activity for formic acid electro-oxidation, which agrees well with previous studies on $\mathrm{Pt}(100)$ single crystal electrodes. The above results suggest that the electrochemical treatment method can be used as a very facile and one-step way to prepare model Pt disk electrode with well-defined (100) preferential surface orientation for the investigation of the structure-sensitive reactions.

Keywords: platinum; electrochemical treatment; electro-oxidation; structure-sensitive; square-wave voltage.

\section{FULL TEXT}


(C) 2016 The Authors. Published by ESG (www.electrochemsci.org). This article is an open access article distributed under the terms and conditions of the Creative Commons Attribution license (http://creativecommons.org/licenses/by/4.0/). 